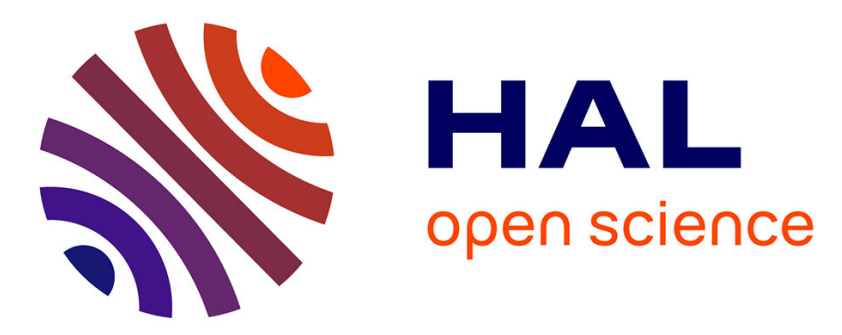

\title{
Optical far-field and near-field observations of the strong angular dispersion in a lithium niobate photonic crystal superprism designed for double (passive and active) demultiplexer applications
}

S. Diziain, J. Amet, F.I. Baida, M.-P. Bernal

\section{- To cite this version:}

S. Diziain, J. Amet, F.I. Baida, M.-P. Bernal. Optical far-field and near-field observations of the strong angular dispersion in a lithium niobate photonic crystal superprism designed for double (passive and active) demultiplexer applications. Applied Physics Letters, 2008, 93, pp.261103. 10.1063/1.3059558 . hal-00350001

\section{HAL Id: hal-00350001 \\ https://hal.science/hal-00350001}

Submitted on 12 May 2021

HAL is a multi-disciplinary open access archive for the deposit and dissemination of scientific research documents, whether they are published or not. The documents may come from teaching and research institutions in France or abroad, or from public or private research centers.
L'archive ouverte pluridisciplinaire HAL, est destinée au dépôt et à la diffusion de documents scientifiques de niveau recherche, publiés ou non, émanant des établissements d'enseignement et de recherche français ou étrangers, des laboratoires publics ou privés. 


\title{
Optical far-field and near-field observations of the strong angular dispersion in a lithium niobate photonic crystal superprism designed for double (passive and active) demultiplexer applications
}

\author{
Séverine Diziain, ${ }^{\text {a) }}$ Julien Amet, Fadi I. Baida, and Maria-Pilar Bernal \\ Département d'Optique, Institut FEMTO-ST, CNRS UMR6174, Université de Franche-Comté, \\ 16 route de Gray, 25030 Besançon Cedex, France
}

(Received 24 October 2008; accepted 6 December 2008; published online 29 December 2008)

\begin{abstract}
We report on a lithium niobate photonic crystal (PC) superprism device designed for double demultiplexer applications. In fact, the strong angular beam steering cannot only be reached by passively tuning the wavelength but it can also be actively controlled by the Pockels effect enhanced due to the slow light phenomenon. The performance of the passive device is demonstrated by measuring its transmission properties. Optical far field and near-field experiments, corroborated by two-dimensional finite difference time domain (2D-FDTD) calculations, exhibit an angular dispersion of $1.5^{\circ} / \mathrm{nm}$. A value as high as $4.3^{\circ} / \mathrm{nm}$ is expected by improving the PC design as supported by 2D-FDTD simulation. (c) 2008 American Institute of Physics.
\end{abstract}

[DOI: $10.1063 / 1.3059558]$

Since the innovative work of Yablonovitch, ${ }^{1}$ photonic crystals (PCs) appear as challenging compact tools for spectrally and spatially controlling the light in a way that was until then impossible with conventional optics. ${ }^{2}$ Among all applications based on PCs, the superprism (SP) effect, whereby the direction of the light propagation is strongly sensitive to a small variation in the wavelength or of the angle of incidence, offers the ability to bend a light beam much more than it would be possible with prisms or gratings. This unusual dispersion of light in PCs is of great interest for integrated optics applications such as optical wavelength demultiplexers (WDMs). Several studies have been carried out to theoretically design efficient PC superprism (PCSP) devices and their performances have been characterized. The stronger light deviation as high as $5 \% \mathrm{~nm}$ was experimentally obtained in a three-dimensional PC. ${ }^{3}$ Recently, a beam steering of $4 \% \mathrm{~nm}$ was reached in a two-dimensional PC (2D-PC), ${ }^{4}$ but most of the SPs based on 2D-PCs exhibit, in the visible and near-infrared regions, a dispersion of light of around $1 \% \mathrm{~nm}^{5-8}$ All these PCSPs were developed for passive applications, but a convenient way is to control the beam steering by external parameters. Only a few theoretical studies have been devoted to such tunable PCSPs, ${ }^{9-13}$ and no tunable PCSP has been experimentally demonstrated to date.

In this letter, we are interested in a 2D-PCSP fabricated in a x-cut lithium niobate (LN) substrate. This material, characterized by high electro-optic coefficients, enables the fabrication of tunable PCs whose properties can be controlled by an enhanced Pockels effect induced by slow light phenomenon. ${ }^{14}$ The proposed device was designed for double demultiplexer applications in the telecom wavelength range centered around $1.55 \mu \mathrm{m}$. First, a strong beam steering of $4.3^{\circ} / \mathrm{nm}$ is theoretically expected when changing the incident wavelength, and second, the deflection of each monochromatic beam can be controlled by the enhanced Pockels effect. In order to ensure the highest electro-optic coefficient, planar electrodes will be deposited on the surface

${ }^{\text {a)} E l e c t r o n i c ~ m a i l: ~ s e v e r i n e . d i z i a i n @ u n i v-f c o m t e . f r . ~}$ of the device on both sides of the waveguide (WG). With a calculated enhancement factor of 3 , an angular beam steering of $50^{\circ}$ is expected for an applied electric field of $4 \mathrm{~V} / \mu \mathrm{m}$ at $1560 \mathrm{~nm}$. The complete theoretical study of this SP based on a plane wave expansion (PWE) method is described in another paper. ${ }^{15}$ Here, we demonstrate the experimental performance of the device in its passive WDM function. Optical far field and near-field measurements display the superrefraction inside the PC. Experimental results are corroborated by simulations based on a homemade 2D finite difference time domain (2D-FDTD) code that takes into account the experimental parameters. ${ }^{16}$

The PC we are interested in consists of a triangular lattice of ten rows composed of circular air holes etched by focused ion beam ${ }^{17}$ into an annealed proton exchange $\mathrm{LN}$ WG with a refractive index of 2.143 at $1.55 \mu \mathrm{m}$. This WG was fabricated by annealing for $9 \mathrm{~h}$ at $333{ }^{\circ} \mathrm{C}$ following 90 min of immersion in benzoic acid at $180{ }^{\circ} \mathrm{C} .{ }^{18}$ It selects only the transverse electric (TE) polarized light, i.e., the component of the electric field that is perpendicular to the axis of the holes, and the guided mode is centered at $1.4 \mu \mathrm{m}$ below the surface. The holes are characterized by a radius $(r)$ of $86 \mathrm{~nm}$ and a depth of $1.5 \mu \mathrm{m}$, while the lattice period $(a)$ is equal to $430 \mathrm{~nm}$. Since a SP effect was theoretically demonstrated in this device for both WDM and tunable applications for an incidence angle of $21^{\circ}$ with respect to the PC ГK direction, ${ }^{15}$ the entrance side of the PC was tilted with an angle of $69^{\circ}$ with respect to the direction of the linear WG that confines the light up to the PC. Figure 1(a) shows the scanning electron microscope (SEM) image of the device. In order to measure the beam deflection for different wavelengths, holes were drilled into a widened planar WG. The optical properties of this device calculated by the PWE method $^{19}$ are summarized in Fig. 1.

The band diagram, shown in Fig. 1(b), exhibits a stop band (SB) from 1340-1546 nm with the particular incidence angle of $21^{\circ}$ with respect to the PC $\Gamma K$ direction. The direction of the refracted beams is obtained from the equifrequency contours that are deduced from the band structure in 


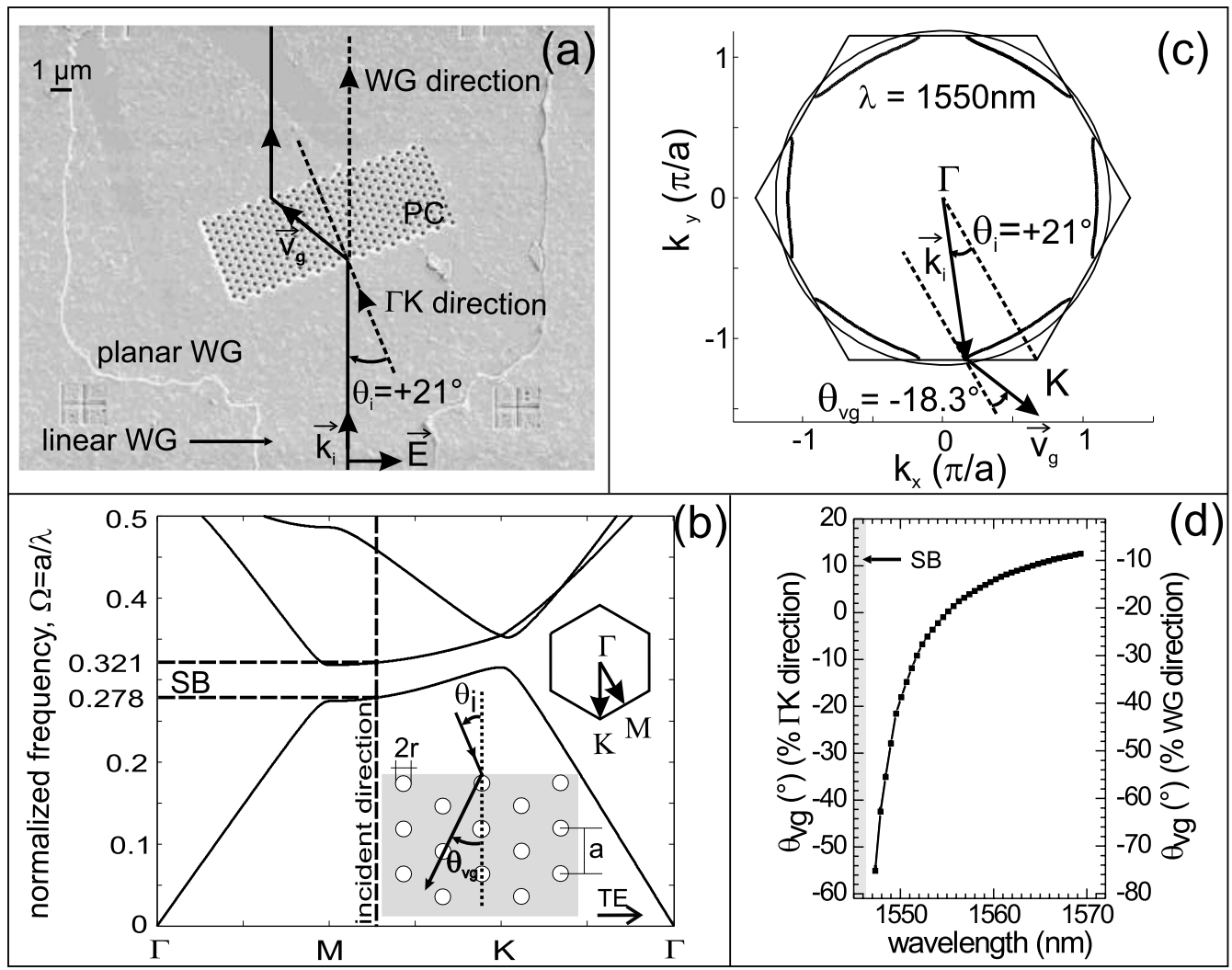

FIG. 1. (a) SEM image of the device. $\Theta_{i}$ : angle of incidence, $v_{g}$ : group velocity. (b) Band diagram of the PC calculated by the PWE method for the TE polarization and $a=430 \mathrm{~nm}, r=86 \mathrm{~nm}$. Inset: schematic of the Brillouin zone and of the PC lattice in the real space. $\Theta_{v}$ : angle of refraction. (c) Equifrequency contours plotted at $1550 \mathrm{~nm}$. (d) Angles of refraction inside the PC (with respect to the PC $\Gamma K$ direction for the left ordinates and with respect to the linear WG axis for the right ordinates) as a function of the wavelength for $\Theta_{i}=21^{\circ}$ with respect to the PC $\Gamma K$ direction.

various directions at a fixed frequency. As an example, Fig. 1(c) shows such dispersion surface calculated at $1550 \mathrm{~nm}$. For a given incidence angle $\left(\Theta_{i}\right)$, the angle of refraction $\left(\Theta_{v_{g}}\right)$ is determined from the conservation of the wave vector component parallel to the PC entrance side and the group velocity direction that is perpendicular to the equifrequency contours. Angles of refraction calculated for an incidence angle of $21^{\circ}$ with respect to the PC $\Gamma K$ direction are reported in Fig. 1(d). This curve displays a strong negative refraction for wavelengths near the SB edge and, when decreasing the energy, the light beam deflects toward the linear WG direction and then crosses it. A strong beam steering average of $4.3 \% \mathrm{~nm}$ is theoretically expected for wavelengths ranging from 1547 to $1562 \mathrm{~nm}$.

The transmission properties of this device were first characterized by optical far field measurements. A tunable laser beam with wavelengths between 1548 and $1576 \mathrm{~nm}$ was polarized in the TE mode and injected into the linear WG. The beam, refracted by the PC, propagated along the planar WG and reached the device output facet which was imaged with an infrared camera using an infrared microscope objective. To compare transmitted signals at different wavelengths, the same laser powers were injected for each wavelength and the spectral response of the detection system was taken into account. Horizontal cross sections, i.e., parallel to the planar WG, were plotted on these images at the position of the beam center and were normalized with respect to the maximum of the transmitted signal. They are reported in Fig. 2(a).

The zero coordinate of the vertical axis corresponds to the position of the linear WG, i.e., to the position of the incident beam center. From 1545 to $1556 \mathrm{~nm}, 35 \%$ of light is transmitted without undergoing any deflection, while at $1556 \mathrm{~nm}$ the transmission increases and the mode is suddenly deflected with an angle of $-23^{\circ}$ with respect to the linear WG direction or $-2^{\circ}$ with respect to the PC $\Gamma K$ direc-

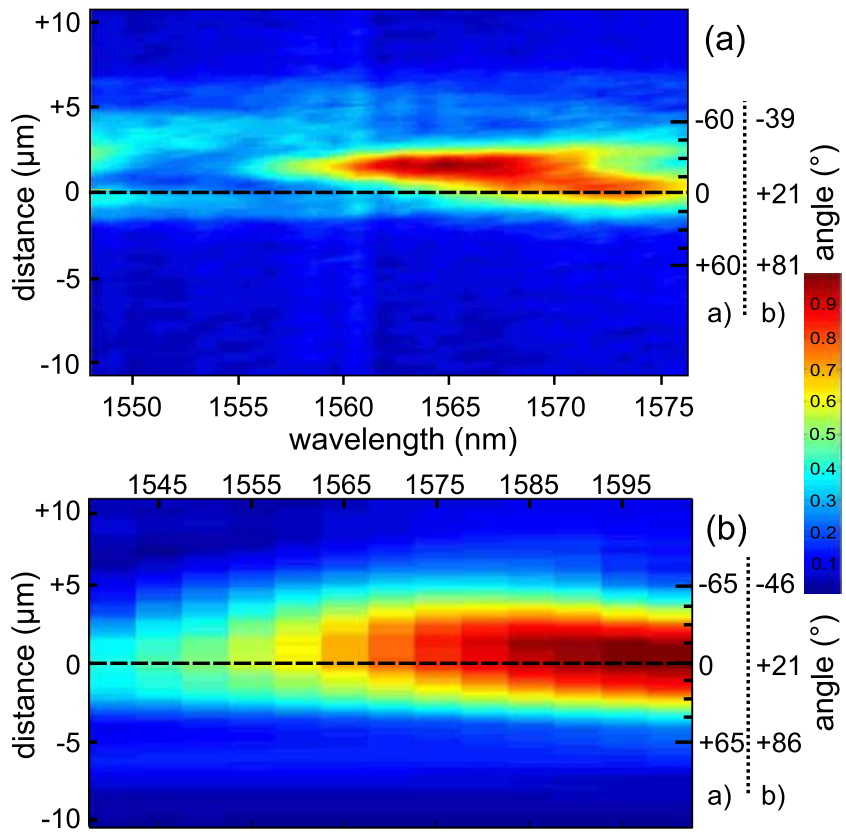

FIG. 2. (Color online) (a) Experimental and (b) 2D-FDTD calculated mode profiles plotted as a function of the wavelength. Angles are expressed with respect to the linear WG axis in the (a) columns and with respect to the PC $\Gamma K$ direction in the (b) columns. For a better legibility, the calculated Poynting vector is raised to the power of 0.2 . 
tion. The wavelength of $1556 \mathrm{~nm}$, from which the transmission increases so far as to reach a value of 1 , defines the edge of the measured SB. From $1556 \mathrm{~nm}$, the angle of the light deviation increases with the wavelength so that the light bends to reach the linear WG direction. Also, from $1572 \mathrm{~nm}$, the mode goes through the PC without undergoing any deviation. An angular beam steering of $1.4 \% \mathrm{~nm}$ is thus experimentally demonstrated for wavelengths ranging from 1556 to $1572 \mathrm{~nm}$. This value lower than the one of $4.3^{\circ} / \mathrm{nm}$ foreseen by PWE calculations is in accordance with the fact that the experimental SB edge is shifted toward low energies, as compared to the calculated one, so that the strong theoretical negative refraction expected for wavelengths close to the edge of the theoretical SB (at $\lambda=1546 \mathrm{~nm}$ ) cannot occur. Discrepancies between theoretical forecasts and experiments are due to the fact that the PWE method assumes the PC as an infinite structure instead of a PC with a limited number of hole rows. The finite size of the PC also explains why the transmitted signal inside the SB is different from zero. To take into account the true size of the PC, 2D-FDTD calculations based on an homemade code were performed. ${ }^{16}$ The geometry of the WGs and the ten rows of holes that composed the PC were modeled as well as the oblique incidence of the Gaussian beam. The transmission of the device was calculated at each $5 \mathrm{~nm}$ step for wavelengths ranging from 1540 to $1600 \mathrm{~nm}$. Such large calculation step is enough to model the behavior of the mode transmission and allows a reduced computer memory size. Figure 2(b) shows the Poynting vector calculated along the direction perpendicular to the linear WG axis at a distance of $6 \mu \mathrm{m}$ from the output side of the PC. It looks quite similar to the measured mode shown in Fig. 2(a). Actually, the FDTD SB edge is found to be at $1560 \pm 2.5 \mathrm{~nm}$ where the angle of refraction drops from $0^{\circ}$ to $20^{\circ}$ with respect to the linear WG axis. Unlike the experimental results, this angle keeps close to $-20^{\circ}$ for a larger range of wavelengths, and the transmission inside the SB is only $1 \%$ compared to the $35 \%$ experimentally found. The differences between FDTD calculations and experimental results lie in the fact that the 2D-FDTD code cannot model the finite depth of the holes nor their conical shape that is responsible for losses and modifications in the PC transmission properties. ${ }^{20}$

In order to confirm the passive WDM capability of the device, near-field optical inspection experiments were also performed. A dielectric tip collecting the evanescent field scanned the sample surface in the direction perpendicular to the linear WG at a distance of several hundreds of nanometers from the output side of the PC. The optical near-field intensities, normalized with respect to the maximum of the transmitted signal outside the SB, are plotted in Fig. 3 for two different wavelengths.

The curves are characterized by the central peak of interest and satellite peaks with lower intensities that are due to the spatial frequencies of the incident Gaussian beam that are different from the relevant incident wave vector $\left(k_{i}\right)$. At $1550 \mathrm{~nm}, 55 \%$ of light is transmitted without deviation, while at $1560 \mathrm{~nm}$ outside the SB, $100 \%$ of light is transmitted and deflected with an angle of $-15^{\circ}$ with respect to the linear WG axis. The angular beam steering of $1.5^{\circ} \mathrm{nm}$ thus measured by optical near-field experiments for wavelengths ranging from 1550 to $1560 \mathrm{~nm}$ agrees with the optical far field measurements. In order to improve the angular devia-

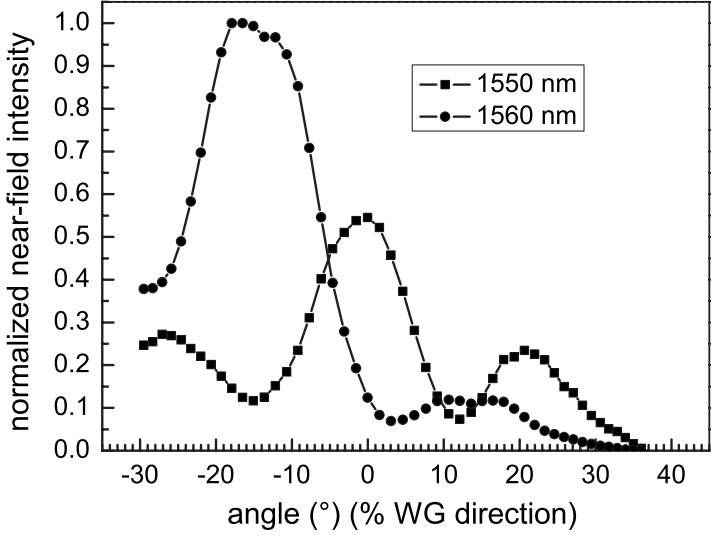

FIG. 3. Near-field intensities as a function of the angular deviation measured with respect to the linear WG direction.

tion, we propose to etch a PC with a larger number of hole rows. 2D-FDTD calculations, not shown here, exhibit a SB similar to the one foreseen by PWE simulations as soon as the PC is composed of 30 rows of holes. By shifting the SB edge toward higher energy, the angular beam steering will be increased and a value close to $4.3 \% \mathrm{~nm}$ will be expected around $1554 \mathrm{~nm}$.

In conclusion, the performance of a LN PCSP designed for both passive and active applications has been demonstrated. An angular beam steering of $1.5 \% \mathrm{~nm}$ was measured with a very small PC $\left(10 \times 4 \mu \mathrm{m}^{2}\right)$. By increasing the size of the PC $\left(10 \times 12 \mu \mathrm{m}^{2}\right)$, an angular deviation as high as $4.3^{\circ} / \mathrm{nm}$ is expected.

The authors are grateful to EU for its financial support under Grant No. STREP 033297 3D-DEMO and to R. Salut and G. Ulliac of MIMENTO for sample fabrication.

${ }^{1}$ E. Yablonovitch, Phys. Rev. Lett. 58, 2059 (1987).

${ }^{2}$ J. D. Joannopoulos, R. D. Meade, and J. N. Winn, Photonic Crystals: Molding the Flow of Light (Princeton University Press, Princeton, NJ, 1995).

${ }^{3}$ H. Kosaka, T. Kawashima, A. Tomita, M. Notomi, T. Tamamura, T. Sato, and S. Kawakami, J. Lightwave Technol. 17, 2032 (1999).

${ }^{4}$ B. Momeni, M. Chamanzar, E. Hosseini, M. Askari, M. Soltani, and A. Adibi, Opt. Express 16, 14213 (2008).

${ }^{5}$ J. J. Baumberg, N. M. B. Perney, M. C. Netti, M. D. C. Charlton, M. Zoorob, and G. J. Parker, Appl. Phys. Lett. 85, 354 (2004).

${ }^{6}$ A. Lupu, E. Cassan, S. Laval, L. E. Melhaoui, P. Lyan, and J. M. Fedeli, Opt. Express 12, 5690 (2004).

${ }^{7}$ A. Lupu, A. de Lustrac, A. Ourir, X. Checoury, J.-M. Lourtioz, E. Centeno, D. Cassagne, J.-P. Albert, F. Pommereau, and L. Legouezigou, Opt. Express 14, 2003 (2006).

${ }^{8}$ L. Wang, W. Jiang, X. Chen, L. Gu, J. Chen, and R. Chen, J. Appl. Phys. 101, 114316 (2007)

${ }^{9}$ D. Scrymgeour, N. Malkova, S. Kim, and V. Gopalan, Appl. Phys. Lett. 82, 3176 (2003).

${ }^{10}$ N. Panoiu, M. Bahl, and R. Osgood, Opt. Lett. 28, 2503 (2003).

${ }^{11}$ G. Alagappan, X. Sun, P. Shum, and M. Yu, Opt. Lett. 31, 1109 (2006).

${ }^{12}$ T.-H. Pei and Y.-T. Huang, Jpn. J. Appl. Phys., Part 2 46, L593 (2007).

${ }^{13}$ J. Amet, F. Baida, G. Burr, and M.-P. Bernal, Photonics Nanostruct. Fundam. Appl. 6, 47 (2008).

${ }^{14}$ M. Roussey, M.-P. Bernal, N. Courjal, D. V. Labeke, and F. Baida, Appl Phys. Lett. 89, 241110 (2006).

${ }^{15}$ J. Amet, F. I. Baida, and M.-P. Bernal, J. Opt. Soc. Am. B (unpublished)

${ }^{16}$ F. I. Baida, D. V. Labeke, Y. Pagani, B. Guizal, and M. A. Naboulsi, J. Microsc. 213, 144 (2004).

${ }^{17}$ F. Lacour, N. Courjal, M. P. Bernal, A. Sabac, C. Bainier, and M. Spajer, Opt. Mater. 27, 1421 (2005).

${ }^{18}$ J. Jackel, C. Rice, and J. Veselka, Appl. Phys. Lett. 41, 607 (1982).

${ }^{19}$ S. Guo and S. Albin, Opt. Express 11, 167 (2003).

${ }^{20}$ G. Burr, S. Diziain, and M. Bernal, Opt. Express 16, 6302 (2008). 